Received Date: 27-Oct-2011

Revised Date : 12-Dec-2011

Accepted Date: 08-Jan-2012

Article type : Review

Review Article

\title{
Alcohol-associated risks for young adults with Type 1 diabetes: a narrative review
}

K. Barnard ${ }^{1}$, J. M. A. Sinclair ${ }^{2}$, J. Lawton ${ }^{3}$, A. J. Young ${ }^{4}$ and R. I. G. Holt ${ }^{5}$

${ }^{1}$ NETSCC, University of Southampton, ${ }^{2}$ Clinical and Experimental Sciences Academic Unit, Faculty of Medicine, University of Southampton, Southampton, ${ }^{3}$ Research Unit in Health, Behaviour and Change, University of Edinburgh, Edinburgh, ${ }^{4}$ Wessex Institute, University of Southampton and ${ }^{5}$ Human Development and Health Academic Unit, Faculty of Medicine, University of Southampton, Southampton, UK

Correspondence to: Dr Katharine Barnard CPsychol, NETSCC, University of Southampton, Alpha House, Southampton Science Park, Chilworth, Southampton SO16 7NS, UK. E-mail: k.barnard@ southampton.ac.uk

Running head: Alcohol-associated risks for young adults with Type 1 diabetes $\bullet K$. Barnard et al.

This article has been accepted for publication and undergone full peer review but has not been through the typesetting, pagination and proofreading process which may lead to differences between this version and the Version of Record. Please cite this article as an 'Accepted Article', doi: 10.1111/j.1464-5491.2012.03579.x

(C) 2012 The Authors. Diabetic Medicine (C) 2012 Diabetes UK 


\section{Abstract}

Aim To undertake a narrative review of the impact and pattern of alcohol consumption in young adults with Type 1 diabetes.

Methods Data sources: MEDLINE, EMBASE, PsycINFO, The Cochrane Library, Web of Science, meeting abstracts of the European Association for the Study of Diabetes, the American Diabetes Association and Diabetes UK, Current Controlled Trials, ClinicalTrials.gov, UK Clinical Research Network, scrutiny of bibliographies of retrieved papers and contact with experts in the field. Inclusion criteria: relevant studies of any design of alcohol consumption and young adults with Type 1 diabetes (age 14-25 years) were included. The key outcomes were the quantity, pattern and impact of alcohol consumption, the effect on diabetes control and the effect of interventions to minimize the risks of alcohol for this population.

Results Six articles and two conference abstracts met the inclusion criteria. There were six cross-sectional studies, one qualitative study and one within-subjects design study. Quality of studies was variable. Alcohol use amongst young adults with Type 1 diabetes was reported to be common and potentially harmful. There was a paucity of evidence on interventions to minimize the risks of alcohol in this target group.

Conclusions Research is required to understand the social context of alcohol consumption in this population with a view to developing appropriate interventions to minimize the risks associated with its use.

Keywords alcohol, alcohol consumption, Type 1 diabetes, young adults 


\section{Introduction}

Alcohol is by far the most commonly used intoxicating substance and has played a central role in almost all human cultures since Neolithic times [1]. Whilst alcohol consumption is common and moderate drinking is the norm in many cultures, some countries, such as the UK, experience more alcohol-related problems than others such as Norway, China or Turkey [2].

Public health estimates of alcohol use vary widely and include information on the patterns of alcohol use and the prevalence of harmful and hazardous use, as well as alcohol dependence. Eight-seven per cent of the population (aged 16 years or over) in England consumed alcohol in 2008 [3]. Whilst people with diabetes tend to drink less than their counterparts without diabetes, approximately $26 \%$ of adolescents with Type 1 diabetes report ongoing or sustained alcohol use [4]. In one study, the rates of alcohol use were $30.1 \%$ in those with diabetes compared with $39.2 \%$ in those without diabetes $(P<0.01)$ [5]. Although fewer individuals with Type 1 diabetes drink alcohol, the potential and severity of harm associated with alcohol use is higher in people with diabetes than in the general population: in addition to the range of physical, psychological and social harms experienced by the rest of the population, there are also specific effects of alcohol on diabetes and glycaemic control. Alcohol may have a direct adverse effect on diabetes control; lower levels of self-management (e.g. forgetting to inject insulin or monitor blood glucose) or engaging in risky behaviours [6], which in turn may have a negative impact on diabetes control, quality of life and risk of depression [7]. Acute alcohol ingestion may induce an altered state of consciousness, resulting in reduced diabetes self-care. Other diabetes-related health risks associated with alcohol include increased glucose lability [7], hypoglycaemia and ketoacidosis [8].

Young adulthood is a time of increasing responsibility and independence. New experiences are acquired, such as moving away from home, increased financial independence and changes in peer groups and other relationships. Increased access to alcohol, with fewer familial restrictions or monitoring is associated with increased alcohol consumption and alcohol-associated risk behaviours [9]. Preliminary data indicate harmful alcohol use in young adults with Type 1 diabetes represents a serious 
public health problem, although prevalence estimates vary widely from abstinence to in excess of 20 units a week [9]. There is likely to be an underestimation in clinical studies, owing to under-reporting by participants who may fear the consequences of disclosure [10].

The aim of this review is to gain a greater understanding of the pattern of alcohol consumption amongst young adults with Type 1 diabetes and explore the motivations and impact of this behaviour.

\section{Methods}

The general principles recommended by the Centre for Reviews and Dissemination [11] were followed. Studies were eligible for inclusion if they met the following criteria: participants were young adults with Type 1 diabetes (to include age range 1425 years), reported alcohol consumption and self-management behaviours. Study designs of any type were acceptable if they reported alcohol use in the target group and were published in peer-reviewed English-language journals.

The following electronic databases were searched using Scopus abstract and citation database: The Cochrane Library (Issue 1, 2010); MEDLINE (1948-May 2011); EMBASE (1974-May 2011); Science Citation Index Expanded (1970-March 2010); Social Sciences Citation Index (1970-March 2010); Conference Proceedings Citation Index-Science (1990-present); PsycINFO (1967-March 2010). Additional sources were hand searched, including meeting abstracts of the European Association for the Study of Diabetes, the American Diabetes Association, Diabetes UK; the Psychosocial Aspects of Diabetes study group; Current Controlled Trials, ClinicalTrials.gov and UK Clinical Research Network. The reference lists of all studies that met the inclusion criteria were searched manually.

Identified abstracts were examined for inclusion by two researchers (KB and AJY) with full-text papers obtained and reviewed independently by both investigators. A quality assessment for each included study was performed using tools appropriate to the study design based on the 'Crombie' criteria for assessment of cross-sectional studies [12]. This, in conjunction with the Critical Appraisal Skills Programme (CASP) tool, 
covers appropriateness of design and methods, quality of reporting and conclusions drawn. Quality was assessed independently by two investigators (KB and AJY) and data were extracted independently (by KB and AJY) using a standardized data extraction table. A meta-analysis was not possible because of the heterogeneity of studies, which included differences in design and outcome measures. Studies were therefore subjected to a critical appraisal and narrative synthesis by using a textual approach to explore the content of included papers while focusing on a broad range of questions [12,13].

\section{Results}

Three hundred and twenty-one abstracts were identified, of which 45 were selected for retrieval of full-text articles. Eight studies met the inclusion criteria and were included in the review (Fig. 1). Young adults were included in all studies; however, two studies were specifically about illicit drug use rather than alcohol consumption $[10,14]$ and therefore were excluded.

Six studies with a total 922 participants ranging from 12 [15] to 679 [16] were included. Two conference abstracts with a total of 88 participants ranging from 27 [9] to 61 [17] were also included. Only Ramchandani et al. [6], Neupane and Imtiaz [9], Ismail et al. [15] and Kamal et al. [17] reported insulin regimen and only Hanna [18] and Kamal et al. [17] reported $\mathrm{HbA}_{1 \mathrm{c}}$ results. Six articles reported cross-sectional studies $[6,9,16,17,18,20]$, one was a qualitative study [19] and one was a within-subjects design [15]. Three studies did not report duration of diabetes [17,19,20], whilst Ramchandani et al. [6] reported a duration of more than 1 year, Hanna [18] a mean duration of 7 years 5 months, Scaramuzza et al. [16] $7 \pm 5$ years, Neupane and Imtiaz [9] a mean duration of 8 years and Ismail et al. [15] a mean duration of 9.4 years.

\section{Articles}

Hanna: Health-compromising behaviour and diabetes mismanagement among adolescents and young adults with diabetes

Hanna [18] examined the relationship between health-compromising behaviour (defined broadly as behaviours that may harm the health of the individual) and age, gender and diabetes mismanagement in 107 participants aged 12-24 years attending 
routine diabetes outpatient appointments. Health-compromising behaviour was assessed by self-report questionnaire; there were 10 questions giving a maximum score of 50 (possible range 10-50). Questionnaire themes included involvement in 'hard drugs', alcohol, smoking, physical violence, driving while drinking and having sexual intercourse as indicators of health-compromising behaviour. Involvement in health-compromising behaviour was defined as a score of $>30.0$.

A significant relationship existed between diabetes mismanagement and age ( $r=0.23, P<0.05)$ and health-compromising behaviour $(r=0.66, P<0.001)$. There was a significant relationship between health compromising behaviour and metabolic control ( $r=0.30, P=0.007)$, but no significant relationship between diabetes mismanagement and metabolic control $(r=0.12, P=0.30)$.

\section{Scaramuzza et al.: Adolescents with Type 1 diabetes and risky behaviour}

This paper reports a cross-sectional questionnaire study of adolescents in 2003-2007 [16]. Participants were recruited from five diabetes camps $(n=215)$ in four cities in Italy (Cagliari, Macugnaga, Portoferraio and Alpe di Siusi). The control group comprised 464 healthy adolescents from high schools in Northern Italy (recruitment period 2005-2006). The questionnaire (designed by the study authors) included items divided into six main categories: personal data, family, drug use, personal problems, sexual behaviour and diabetes mismanagement. Alcohol data were collected under the 'drug use' category. Analyses were conducted separately by gender across cohorts. Among those with Type 1 diabetes, female participants consumed more alcohol than young men $(p<0.05)$, whereas in people without diabetes the opposite was the case $(P \leq 0.05)$, although no specific numbers were reported to support these results. Among those with Type 1 diabetes, $\mathrm{HbA}_{1 \mathrm{c}}$ was higher in those who reported engaging in one or more risky behaviours than those who did not $[12.3 \pm X X \mathrm{mmol} / \mathrm{mol}$ $(8.4 \pm 1.2 \%)$ vs. $11.2 \pm \mathrm{XX} \mathrm{mmol} / \mathrm{mol}(7.8 \pm 0.9 \%), P<0.05]$. Those who engaged in one or more types of risky behaviour were more likely to mismanage their diabetes than those who did not (85 vs. 15\% mismanagement for one type of risky behaviour; 62 vs. $38 \%$ for more types of risky behaviour, respectively) $(P<0.001)$. 
Ramchandani et al.: Self-reported factors that affect glycaemic control in college students with Type 1 diabetes

Ramchandani et al. [6] examined the self-reported impact of different factors on the overall diabetes care of 42 college students with Type 1 diabetes. Three students used insulin pumps while 39 students took between 2 and 5 injections a day (mean $3.3, S D=0.8$ ), of whom more than half took at least four injections daily. Over one third of students $(n=15)$ believed their blood glucose control was better since starting college; $33.3 \%(n=14)$ believed it was worse and $26.2 \%(n=11)$ reported no change; $4.8 \%(n=2)$ reported that they did not know how their blood glucose control had changed.

Factors associated with change in diabetes control were ranked by participants. Alcohol was ranked sixth behind diet, exercise, frequency of self-monitoring of blood glucose, increased responsibility, irregular schedule, fear of hypos. Nine students indicated that alcohol had worsened their control; one said that lack of alcohol had improved their control. On average, $35.7 \%$ of students admitted to drinking alcohol once or twice a week and $23.8 \%$ less than once a week. One third (33.3\%) drank 4-6 drinks in an evening; $28.6 \%$ reported drinking $1-3$ drinks in an evening, while $26.2 \%$ consumed no alcohol. The five heaviest drinkers said they 'downed' alcoholic beverages on an average of 3-4 times a week. Those who drank more often tended to have more drinks in one evening than those who drank less frequently $(P=0.001)$.

Complete sets of $\mathrm{HbA}_{1 \mathrm{c}}$ data obtained from clinicians for 31 students indicated that $58.1 \%(n=18)$ experienced worsened glycaemic control since attending college, despite students reporting otherwise. There was no change in glycaemic control for one student, whilst $12(38 \%)$ had improved control. The clinicians' subjective views on metabolic control were similar to $\mathrm{HbA}_{1 \mathrm{c}}$ clinical outcomes. No data were available on those who did not return questionnaires nor were there data reported on the relationship between $\mathrm{HbA}_{1 \mathrm{c}}$ and alcohol consumption. 
Ismail et al.: Social consumption of alcohol in adolescents with Type 1 diabetes is associated with increased glucose lability, but not hypoglycaemia

This study explored the effects of social consumption of alcohol on glycaemic control of adolescents with Type 1 diabetes by attaching continuous glucose monitoring systems at a weekend when alcohol consumption was planned for one night only [15]. The study period occurred on the night prior to the control period. Of the 22 participants recruited, data from seven men and five women were used for analysis (matched control period data). The Australian Alcohol Guidelines were used to convert the recall of alcohol consumption from the participants to 'standard drinks' data [22].

The mean number of 'standard' alcoholic drinks consumed on the study night was 9.0 (range 3-16) for men and 6.3 (range 3-14) for women. All women consumed premixed sweetened alcoholic drinks ( $5 \%$ alcohol), with only one consuming beer and one consuming wine. Four of the men consumed mixed spirits, one mixed spirits and beer and one beer only. Two of the men had more than seven standard drinks during the study and six of the women had more than five drinks. Six participants reported becoming inebriated and one drank so much they vomited. No participants lost consciousness or took recreational drugs during the study period. There was no significant difference between the overall mean glucose concentration between study and control periods $(P=0.43)$ or in the amount of time spent with high glucose values between study and control periods. Hypoglycaemia occurred for less time following alcohol consumption compared with the control period (16.8 vs. $1.9 \%, P=0.03$ ). Glycaemic variation was significantly greater during the study period when compared with the control period.

\section{Balfe: Healthcare routines of university students with Type 1 diabetes}

This qualitative study explored the benefits and barriers that university students with Type 1 diabetes associated with diabetes self-care routines and their experience of their routine diabetes management at university [19]. From 160 postal invitations, six male and eleven female (10.6\%) students participated in the interview phase of the study. Results indicated that a number of respondents recognized that they regularly consumed alcohol in a way they considered to present risks to their diabetes control. This occurred more often at the start of the academic year and gradually lessened 
towards the end. Furthermore, participants were aware of the 'controlling element' of diabetes, believing that it would shape their practices and identities. Therefore, respondents' reported that, by actively engaging in proactive practices such as alcohol consumption, they could better fit in with their social group, thus enabling them to 'situate, strengthen and embody their identities as normal students'.

Gregory et al.: Do patients with insulin-treated diabetes use alcohol safely?

A questionnaire to ascertain drinking habits, knowledge about alcohol, the effects of alcohol on diabetes and health in general was administered at interview to 39 men and 26 women, aged 18-75 years who consecutively attended a diabetes clinic [20]. Nine participants (14\%, two men) drank no alcohol at all, six (9\%, five men) drank more than the recommended allowances, with the remainder drinking alcohol in moderation, although this was not defined. The authors concluded that there is a need for continuing education for people with diabetes about alcohol and health.

\section{Conference abstracts}

Kamal et al.: The effect of lifestyle factors on the glycaemic control of young Type 1 diabetic patients

Kamal et al. administered lifestyle questionnaires to 23 women and 38 men with Type 1 diabetes aged $21 \pm 0.4$ years to investigate factors associated with transition from teenager to young adulthood [17]. Results showed no significant difference in $\mathrm{HbA}_{1 \mathrm{c}}$ among male and female participants $[11.0 \pm \mathrm{XX} \mathrm{mmol} / \mathrm{mol}(7.7 \pm 0.2 \%)$ vs. $10.8 \pm \mathrm{XX} \mathrm{mmol} / \mathrm{mol}(7.6 \pm 0.3 \%)]$. Furthermore, $\mathrm{HbA}_{1 \mathrm{c}}$ was not associated with alcohol consumption $(P=0.5)$. Alcohol consumption did not significantly influence the frequency of severe hypos $(P=0.38)$. 
Neupane and Imtiaz: Lifestyle, social factors and attitude of patients attending young person diabetes clinic

This abstract reported a study of lifestyle and social factors in 16 men and 13 women with Type 1 diabetes aged 16-25 years attending the young persons' diabetes clinic [9]. Electronic database and hospital notes were searched. Fifty-nine per cent of participants consumed alcohol each week (18\%: > 20 units; 18\%: > 10-20 units; 56\%: $<10$ units reported. Note these figures do not total 59\% and numbers were not given). The authors concluded that advice regarding alcohol, incorporating structured education, should be considered so that young people with diabetes would be able to adapt their lifestyle and consequently improve self-management skills.

\section{Methodological quality of included papers}

Overall, the quality of identified papers was variable, with poor response rates, small participant numbers and lack of generalizability across countries. Using the Critical Appraisal Skills Programme [11], several methodological flaws were identified. Ramchandani et al. [6] provided limited results, failed to report all of the number of students and had a low response rate (31\%). Similarly, whilst Ismail et al. [15] had a higher response rate $(54 \%)$, they had a small sample size $(n=12)$ and only reported percentages rather than participant numbers, so lacked precision. Hanna [18] presents an analysis of differences between two arbitrary groups not identified a priori in the methods or procedure sections. Balfe [19] used qualitative self-report methods of semi-structured interviews and research diaries, but alcohol consumption was not the primary outcome of the study. Scaramuzza et al. [16] had a large number of participants; however, data collection occurred during different time periods, which may have had an impact on the results. The study by Gregory et al. [20] was of good quality, but results were not stratified by age. The abstract of Neupane and Imtiaz [9] did not detail methods and figures reported do not appear to add to the total sample size; whilst Kamal et al. [17] gave no detail on questionnaires completed nor levels of alcohol consumed. 


\section{Discussion}

This review has demonstrated that there is a paucity of evidence on the quantity and pattern of alcohol consumption in young adults with Type 1 diabetes, with little known about the complex social context or personal impact in this potentially vulnerable group. Alcohol consumption is common among young adults with diabetes, as with their peers; however, for this population, the risks associated with diabetes may affect glycaemic control.

No studies were identified that reported interventions to minimize the risks of alcohol consumption for this population, although two concluded that education for people with diabetes was necessary $[17,20]$. Whilst randomized controlled trials represent the gold standard of research evidence, for more complex behaviours with a range of potential outcomes, it may not be possible to capture the depth or richness of data without using qualitative methodology and observational studies. By synthesizing the findings of these diverse studies in this narrative review, a number of themes have been identified.

Four studies found that young adults with Type 1 diabetes regularly drink alcohol $[6,19,16,18]$, which may include binge drinking. One reason given for this by participants was that it helped them to 'fit in' better within their social group. Furthermore, alcohol was used as a tool to resist the 'control' of diabetes on their lifestyles and identities. Rather than be seen as 'diabetic', it was more important for those with diabetes to integrate with their peers than to maintain optimal diabetes control in social situations [19].

It is apparent that young adults with Type 1 diabetes recognize that alcohol may impair their diabetes control, but this did not figure highly in their priorities for change $[6,18,19]$. Rather than being unaware of the risks associated with alcohol consumption, they made choices, consciously or subconsciously, that social integration, enjoyment and fitting in with peers were more important than good glycaemic control at this stage of their lives [19]. Interestingly, in the Ismail et al. study [15] and the Kamal et al. abstract [17], alcohol consumption was not associated with hypoglycaemia, as would be expected from the glycaemic-lowering effect of alcohol 
[22]. This may have resulted from the high consumption of sweetened drinks favoured by young adults, such as 'alcopops'. Nevertheless, the consumption of alcohol was associated with greater glucose variability. Scaramuzza et al. [16] reported increased $\mathrm{HbA}_{1 \mathrm{c}}$ with risk-taking behaviour such as alcohol consumption, but did not present specific figures to support this. The data from the Hanna study [18] (in what appears to be a post hoc analysis) suggest that health-compromising behaviours may have a negative impact on metabolic control despite people not acknowledging diabetes mismanagement, a finding which requires further exploration.

The provision of better health care to young people with Type 1 diabetes relies on an acceptance that alcohol use occurs and clinicians need to be educated on how best to encourage patients' self-management in this area. This aspiration is hampered because the context in which young adults with diabetes consume alcohol is poorly understood. Greater understanding of the levels of health literacy in relation to alcohol and the decision-making processes driving alcohol consumption and diabetes selfmanagement is needed in order to provide best practice advice for healthcare professionals in this context.

Two studies reported a significant relationship between health-compromising behaviours and metabolic control [16,18] $(P<0.05$ and $P<0.001$, respectively); however, this was not always acted upon by participants. Ramchandani et al. [8] reported that the majority of participants (61.9\%) who drank alcohol also made no change to their diabetes management. Despite believing that their diabetes control was better at college, this belief was not supported by their clinicians' subjective views nor the $\mathrm{HbA}_{1 \mathrm{c}}$ results. It may also be the case that different social contexts affect health behaviours; for example, being at home compared with being on holiday, as reported in the literature for drug use [14]. Provision of some specific advice may be appropriate to target improved diabetes self-care and optimize diabetes control, thus minimizing the risk of long-term complications. 


\section{Limitations}

Given the small number of studies and participants, it is unknown how representative these studies are of the wider population of young adults with Type 1 diabetes. Furthermore, difficulties are acknowledged in terms of drawing comparisons between studies that use different methods and data collection tools. Whilst all attempts were made to ensure as inclusive a search as possible, it is recognized that, because of the content, this may not have been exhaustive. It has been argued that the intense scrutiny and controls imposed by having Type 1 diabetes, such as frequent and regular clinic attendance, increased interference by family members and others, judgemental societal inference regarding expected (if sometimes erroneous) models of behaviour, may lead young adults with Type 1 diabetes to be more secretive and covert about their alcohol use than their peers [7]. This can, in turn, lead to social isolation and increase the risks of psychosocial co-morbidity such as depression [7].

\section{Conclusion}

Pragmatically, young people with Type 1 diabetes will continue to drink alcohol and engage in risky behaviour, irrespective of parental or healthcare advice. So, rather than try to stop them, taking a prohibitionist and patriarchal perspective, we need to help young adults develop best strategies alongside alcohol consumption to maintain good diabetes control and minimize associated risks. Further research is required to explore the social context of alcohol consumption in order to gain a greater understanding to inform development of appropriate interventions to minimize the risks of alcohol for this population.

\section{Competing interests}

Nothing to declare. 


\section{References}

1. The Social Issues Research Centre. Social and Cultural Aspects of Drinking: A Report to the Amsterdam Group. Edinburgh: University of Edinburgh, XXXX. Available at http://www.sirc.org Last accessed XX Xxxx XXXX.

2. WHO. Global Information System on Alcohol and Health (GISAH). XXXX. Available at http://apps.who.int/ghodata/?theme $=$ GISAH\&vid $=52520$ Last accessed 24 August 2011.

3. Fuller E, Jotangia D, Farrell M. Alcohol misuse and dependence. In: McManus S, Meltzer H, Brugha $\mathrm{T}$ et al., eds. Adult Psychiatric Morbidity in England, 2007. Results of a Household Survey. Leeds: NHS Information Centre for Health and Social Care, 2009.

4. Glasgow AM, Tynan D, Schwartz R, Hicks JM, Turek J, Driscol C et al. Alcohol and drug use in teenagers with diabetes mellitus $J$ Adolesc Health 1991; 12: 1114.

5. Martínez-Aguayo A, Araneda JC, Fernandez D, Gleisner A, Perez V, Codner E. Tobacco, alcohol, and illicit drug use in adolescents with diabetes mellitus Paediatr Diabetes 2007; 8: 265-271.

6. Ramchandani N, Cantey-Kiser JM, Alter CA, Brink SJ, Yeager SD, Tamborlane WV et al. Self-reported factors that affect glycemic control in college students with type 1 diabetes. Diabetes Educ 2000; 26: 656-666.

7. Hislop AL, Fegan PG, Schaeppi MJ, Duck M, Yeap BB. Prevalence and associations of psychological distress in young adults with Type 1 diabetes. Diabet Med 2008; 25: 91-96.

8. Scaramuzza AE, De Palma A, Mameli D, Spiri D, Santoro L, Zuccutti GV. Adolescents with Type 1 diabetes and risky behaviour. Acta Paediatr 2010; 99: 1237-1241.

9. Neupane S, Imtiaz KE. Lifestyle, social factors and attitudes of patients attending young persons diabetes clinic. Diabet Med 2007; 24: 30-121.

10. Lee P, Greenfield JR, Campbell LV. Managing young people with Type 1 diabetes in a 'rave' new world: metabolic complications of substance abuse in Type 1 diabetes. Diabet Med 2009; 26: 328-333.

11. Centre for Reviews and Dissemination (CRD). CRD's Guidance for Undertaking Reviews in Healthcare. York: University of York, 2009.

12. Ring et al. A Guide to Synthesising Qualitative Research for Researchers Undertaking Health Technology Assessments and Systematic Reviews. Stirling: NHS Quality Improvement-Scotland, University of Stirling, 2010. 
13. Spencer et al. Quality in Qualitative Evaluation: A Framework for Assessing Research Evidence. London: Government Chief Social Researcher's Office, Cabinet Office, 2003.

14. Bellis MA, Hughes $K$, Bennett $A$, Thomson R. The role of an international nightlife resort in the proliferation of recreational drugs. Addiction 2003; 98: 1713-1721.

15. Ismail D, Gebert R, Vuillermin PJ, Fraser L, McDonnell CM, Donath SM et al. Social consumption of alcohol in adolescents with Type 1 diabetes is associated with increased glucose lability, but not hypoglycaemia. Diabet Med 2006; 23: 830833.

16. Scaramuzza AE, De Palma A, Mameli C, Spiri D, Santoro L, Zuccotti GV. Adolescents with type 1 diabetes and risky behaviour. Acta Paediatr 2010; 99: 1237-1241.

17. Kamal AD, Smith D, Kesson CM, Rooney DP. The effect of lifestyle factors on the glycaemic control of young Type 1 diabetic patients. Diabetes UK. Diabet Med XXXX; 19: S28-115.

18. Hanna KM. Health-compromising behaviour and diabetes mismanagement among adolescents and young adults with diabetes. Diabetes Educ 2001; 27: XXX-XXX.

19. Balfe M. Healthcare routines of university students with Type 1 diabetes. $J A d v$ Nurs 2009; XX: 2367-2375.

20. Gregory R, Inglesfield J, Molloy O, Yateman N. Do patients with insulin-treated diabetes use alcohol safely? Practical Diabetes 1992; 9: XX-XX.

21. National Health and Medical Research Council. Australian Alcohol Guidelines: Health Risks and Benefits. DS9. XXXX. Available at hhtp://www7.health.gov.au Last accessed XX XXXXX XXXX.

22. Kerr D, Macdonald IA, Heller SR, Tattersall RB. Alcohol causes hypoglycaemic unawareness in healthy volunteers and patients with Type 1 (insulin-dependent) diabetes. Diabetologia 1990; 33: 216-221. 


\section{Supporting Information}

Additional Supporting Information may be found in the online version of this article:

Table S1. Outcome measures of included articles-intervention studies.

Please note: Wiley-Blackwell are not responsible for the content or functionality of any supporting materials supplied to the authors. Any queries (other than for missing material) should be directed to the corresponding author for the article. 
Figure 1 Review flow chart of identified studies.

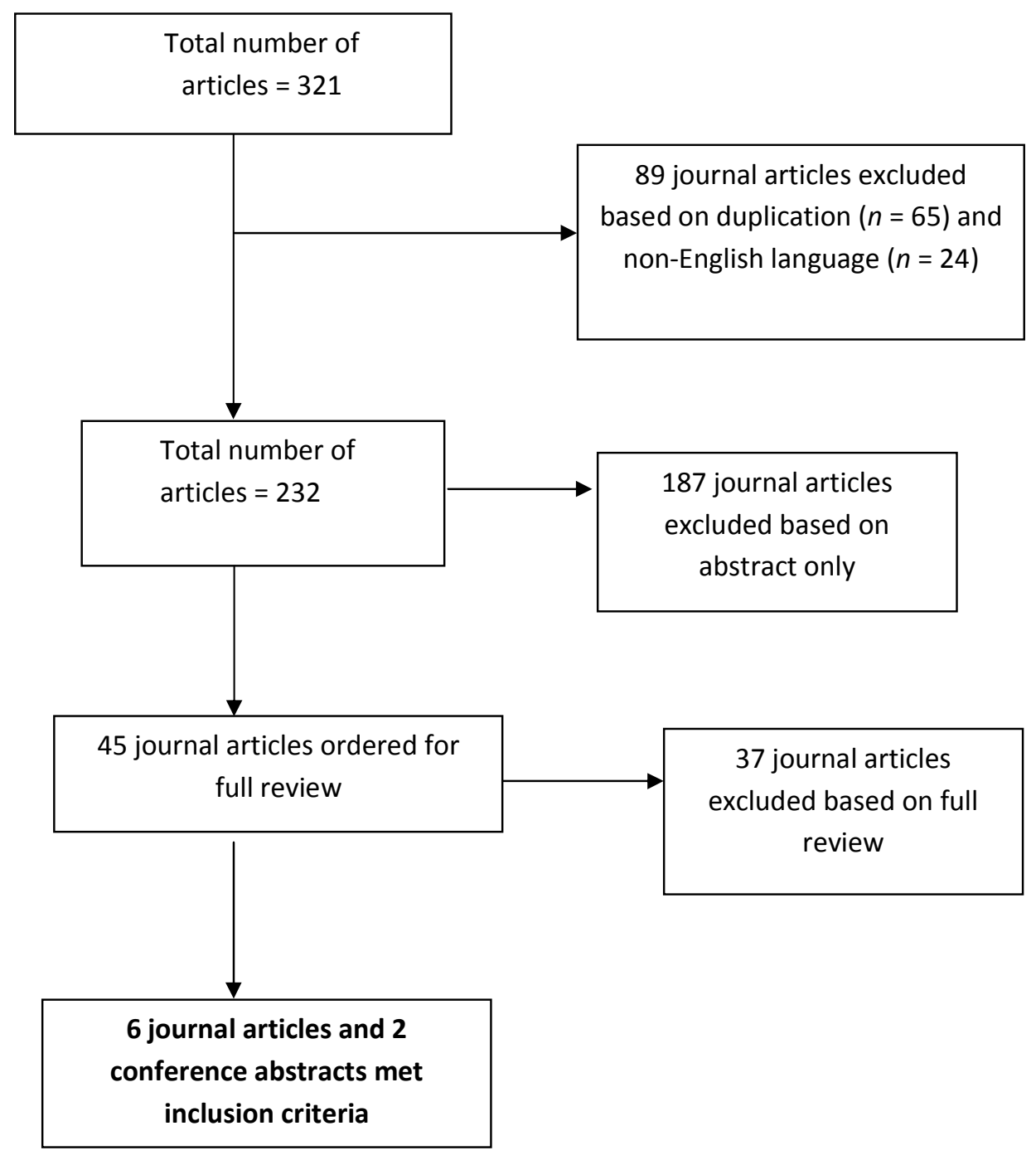


Table 1 Data extraction from included articles-intervention studies

\begin{tabular}{|c|c|c|c|c|c|c|c|}
\hline Date & First author and brief title & Study design & $\begin{array}{l}\text { Number of } \\
\text { participants }\end{array}$ & $\begin{array}{l}\text { Alcohol } \\
\text { use }\end{array}$ & Age & $\begin{array}{l}\text { Duration of } \\
\text { diabetes }\end{array}$ & Insulin regimen \\
\hline 1992 & $\begin{array}{l}\text { Gregory: Do patients use alcohol } \\
\text { safely? [20] }\end{array}$ & Cross-sectional & 65 & Yes & $18-75$ years & Not reported & Not reported \\
\hline 2000 & $\begin{array}{l}\text { Ramchandani: Factors affecting } \\
\text { glycaemic control [6] }\end{array}$ & Cross-sectional & 42 & Yes & $\begin{array}{l}\text { College } \\
\text { students }\end{array}$ & $>1$ year & $\begin{array}{l}39 \text { multiple daily injection; } 3 \\
\text { continuous subcutaneous insulin } \\
\text { infusion }\end{array}$ \\
\hline 2001 & $\begin{array}{ll}\text { Hanna: } & \text { Health-compromising } \\
\text { behaviour [18] }\end{array}$ & Cross-sectional & 107 & Yes & $12-24$ years & $\begin{array}{l}7 \text { years } 5 \text { months } \\
\text { (sD } 4 \text { years } \\
4 \text { months) }\end{array}$ & Not reported \\
\hline 2006 & $\begin{array}{l}\text { Ismail: Social consumption of alcohol } \\
\text { [15] }\end{array}$ & Within subjects & 22 & Yes & $17-19$ years & $\begin{array}{l}9.4 \text { years mean } \\
\text { ( } 3-16.3 \text { years) }\end{array}$ & Injection therapy \\
\hline 2008 & \begin{tabular}{lll} 
Balfe: Healthcare & \multicolumn{2}{l}{ routines of } \\
university students & with Type 1 \\
diabetes [19] & &
\end{tabular} & Qualitative & 17 & Yes & $18-25$ years & Not reported & Not reported \\
\hline 2009 & $\begin{array}{l}\text { Scaramuzza: Adolescents with Type } 1 \\
\text { diabetes and risky behaviour [16] }\end{array}$ & Cross-sectional & 679 & Yes & $14 \pm 2$ years & $7 \pm 5$ years & Not reported \\
\hline \multicolumn{8}{|c|}{ Conference abstracts } \\
\hline 2002 & $\begin{array}{l}\text { Kamal: Effect of lifestyle factors on } \\
\text { glycaemic control [17] }\end{array}$ & Cross-sectional & 61 & Yes & $21 \pm 0.4$ years & Not reported & Injection therapy \\
\hline 2007 & $\begin{array}{l}\text { Neupane: Lifestyle, social factors and } \\
\text { attidues [9] }\end{array}$ & $\begin{array}{l}\text { Electronic } \\
\text { database/hospital notes } \\
\text { analysis }\end{array}$ & 27 & Yes & $16-25$ years & $\begin{array}{l}8 \text { years mean } \\
\text { (range } 3-16 \text { years) }\end{array}$ & Injection therapy \\
\hline
\end{tabular}

\section{(C) 2012 The Authors. Diabetic Medicine @ 2012 Diabetes UK}

